\title{
E-Commerce web Application by using MERN Technology
}

\author{
Nagothu Diwakar Naidu ${ }^{1}$ | Pentapati Adarsh ${ }^{1} \mid$ Sabharinadh Reddy $^{1}$ | Gumpula Raju ${ }^{1}$ | Uppu Sai Kiran ${ }^{1}$ Vikash \\ Sharma $^{2}$
}

${ }_{1}^{1}$ UG Student, Department of Computer Science, Lovely Professional University, Punjab

${ }^{2}$ Department of Computer Science Engineering, Lovely Professional University,Punjab

To Cite this Article

Nagothu Diwakar Naidu., Pentapati Adarsh., Sabharinadh Reddy., Gumpula Raju., Uppu Sai Kiran \& Vikash Sharma. E-Commerce web Application by using MERN Technology. International Journal for Modern Trends in Science and Technology 7, 1-5 (2021).

\section{Article Info}

Received on 27-March-2021, Revised on 20-April-2021, Accepted on 24-April-2021, Published on 29-April-2021.

\section{ABSTRACT}

In today's generation, most people are using technology for leading their lives and fulfilling their daily needs. In this generation most of us using E-commerce websites for shopping for clothes, groceries, and electronics [1]. We have developed one E-commerce web application by using MERNstack technology as it contains MongoDB, Express.JS framework, React.JS library, Node.JS platform. This application is fully functional with different views for user and admin and it also has integrated with payment gateway for checkout. By using this website we can buy different types of $t$-shirts and we can choose different styles of $t$-shirts based upon customer interests. In this project, we can add different products and can delete them also. We have developed administrative functions for the website such as create a product, create categories, Admin dashboard, Manage products, Manage categories. For customersrs, they can quickly add their items to the cart. Based on the items in the cart then the bill gets generate and the customer can pay by using stripe [2].

KEYWORDS: JavaScript, Software Stack, Framework, Library, Performance Analysis, React.js, MongoDB, Node.js, Express.js

\section{INTRODUCTION}

We all know that technology has become an essential tool for online marketing these days. If we see all over the world most of the people are showing interest to buy things in online. However, we can see that there are many small shops and grocery stores are selling their things offline. With this type of selling most of us will face bad experience. for instance, in some shops seller has the product to sell in the offer but the buyer may not know about it, or the customer may need the product urgently then he will go to the shop, but the product is out of stock, in that case, he will face bad experience. Moreover, in online shopping customers can select a wide range of products based upon their interests and their price also, one can compare prices also from one store to another by using online shopping [3].

By encountering the all problems and weaknesses of the offline shopping system, creating an E-commerce webapplication is necessary for searching and shopping in each shop. These days we have seen so many e-commerce websites are created like Flipkart, Amazon, Myntra one can easily buy their necessary products by using these websites. By using these types of websites one can buy their products by staying in their home. Eventually, we can see the 
difference between the prices of products also as if we see the cost of the product will be slightly high in offline shopping when compared to online shopping.

For creating these types of E-commerce web applications MERN stack will be the best option that can help us for creating the most effective and powerful web applications.

\section{PROBLEM STATEMENT}

The purpose of this project is to makes a web application which will be easier to find interesting clothes and easier to sell goods. This E-commerce web application admin can add some categories like summer sales, winter festival, etc. which will by attracting customers. Customers also can easily search for their favorite goods. They can also buy them easily by just adding to the cart and they can increase or decrease by clicking on the "+" sign and "-" sign. After adding they can check the total amount of the thing which have been added to the cart. A successful payment gateway way enabled so payment can be done by debit card, credit card, and net banking.

\section{E-COMMERCE}

\section{Definition:}

E-commerce is also known as electronic commerce, it is the process of buying and selling products through the internet, and also the transfer of money and the data to complete the process of buying or selling a product [4].

In the early days, e-commerce was not that famous but after increasing the use of mobile phones everyone was choosing the interest in buying things online so, it became popular.

Types of E-commerce:

There are mainly four types of E-commerce business models

\section{B2C (Business to consumer).}

It is a business based upon the internet, By using this model we can sell products to the end-user.

2. B2B(Business to business)

It is a business that will happen between large companies, organizations, and businesses, these days most of e-commerce falls in this category.

3. $\mathrm{C} 2 \mathrm{~B}$ (Consumer to Business)

This type of E-commerce allows that the individuals can sell their goods to Companies

In this type of E-commerce, individuals will assign work to complete in the given time through websites or some electronic medium, in this type, consumers can set their price tag to their work The best example of this type of work is freelancing. 4. $\mathrm{C} 2 \mathrm{C}$ (Consumer To Consumer)

This type of E-commerce connects consumers to consumers to exchange their goods and make their money by charging transactions it will motivate buyers and consumers [5].

\section{ADVANTAGES:}

\section{A HUGE MARKET:}

E-commerce will give you an option to reach customers all over the world, you can buy anything that you want to from your home. Nowadays people are used to doing shopping with their mobiles only. So, it will add an advantage for E-commerce.

\section{WIDE PRODUCT VARIETY:}

In this large world, customers can buy different types of products from different places, we can buy electronics from Russia, shoes from japan, clothes from London and good old international products, the depth and advantage of E-commerce is uncountable.

\section{TRACKING:}

If you order any product in e-commerce you will get the details of where the product is shipping and when it will reach you, you can cancel the product also if you don't like that product after order.

\section{LESS PRICE:}

In E-commerce websites, we can compare the prices of products from one website to another website. In that way, we can easily know that where we will get the product for a lesser price and we will get the basic idea that how much money we can spend to buy a particular product.

\section{MORE CHANCES TO "SELL":}

In the physical stores' merchant can not give the full information about the product, but in the E-commerce store customer can get full information about that product and he can see the reviews of another customer who bought that product previously. In this way, if the product is good it will get more chances to get that product [6].

\section{DISADVANTAGES:}

1. SECURITY:

Even though E-commerce providing more benefits to customers. People are having fear about giving their data to website owners, so it will give security 
issues when we use e-commerce websites for shopping.

\section{TAX:}

If we want to buy a product from e-commerce we will have to pay taxes like GST, it will be different from place to place based upon your distance between you and the product, it will be high when compared to buy in physical stores.

\section{DELAYING IN DELIVERY:}

If we order a product in e-commerce, the order may or may not reach you on time, this is one of the common problems in e-commerce, it will take time-based upon your distance between you and the organization from where you ordered.

\section{TECHNOLOGY COST:}

To create a website will take so much amount, one needs to spend so much money on building an e-commerce website because he needs to check all the possibilities and provide a good security system to that website.

\section{RESEARCH AND DEVELOPMENT}

There are so many applications to build a web application and, in this research, we have taken MERN technologies to use for building a web application.

MERN:

MERN stands for MongoDB Expressjs Reactjs Nodejs. These are the four technologies that help us to construct or to build this web application. MongoDB:

It is an open-source cross-platform program. It comes under the NoSQL database classification. It was a document-oriented database. It uses JSON format documents with optional Schemas

* Data Flexibility available means we can any every data in a separate file

* Large data can be distributed into several connected applications * High speed of fetching of data possible because it only depends on indexing.

* It is a horizontally scalable database so it can handle the data make us easy to distribute to serval machines.

NodeJS:

NodeJS is a runtime javascript environment that works outside the web page. It is mainly used for server-side applications.

* NodeJS is open source and it is free of cost.
* NodeJS uses asynchronous programming by default.

* NodeJS will always store the data in only JSON format.

ExpressJS:

It is a famous Library in node.js used for routing. It has some methods like a router which help to do curd operations like put, get, post, and delete request

* Robust routing

* It will focus on high performance

* It is an HTTP helper like it will redirection, catching.

ReactJS:

React is a library of javascript which is created by Facebook. React is mainly used as a UI which means

Maximum it is used for client-side applications. There are so many libraries like React-dom, React-router-dom, and many more to help to build the frontend of any application.

* The rendering of the page will be much faster than others because it has virtual Dom.

* uses a stable code.

* It has a strong community followed [7].

\section{WEB APPLICATION STRUCTURE}
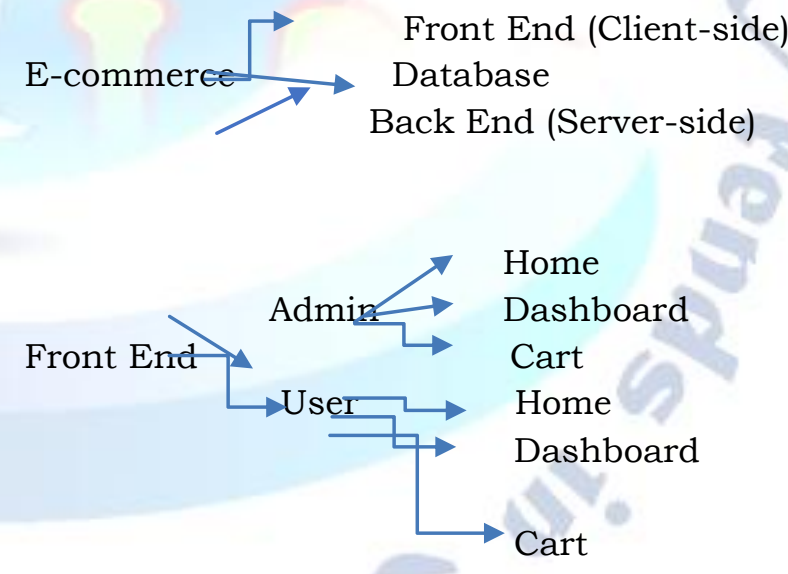

Database $\longrightarrow$ MongoDB

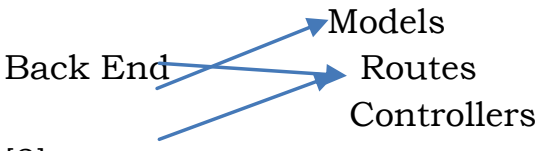

[8].

These are some import modules or parts to be described 


\section{FRONT-END:}

Home Page:

The home page of the web Application mainly contains a list of the t-shirts which are saved in the database. And there some options that will be in the menu bar if the user does not sign in/login in yet then "Sign in" and "Sign up" options will be there. The home page will show you all types of T-shirts and they will be displayed to customers, for example, this homepage has types of T-shirts such as Doggy T-shirt, Coffe T-shirt, friend T-shirt, If we want to add another type of T-shirts we can simply add a wide range of $\mathrm{T}$-shirts, we can give different prices for different $t$-shirts based upon their quality, customers have the facility to add the product to the cart which they like, the customer will have another facility to contact the admin if he has any issues regarding products, prices, and any other issues all these things have appeared preview image is mentioned below:

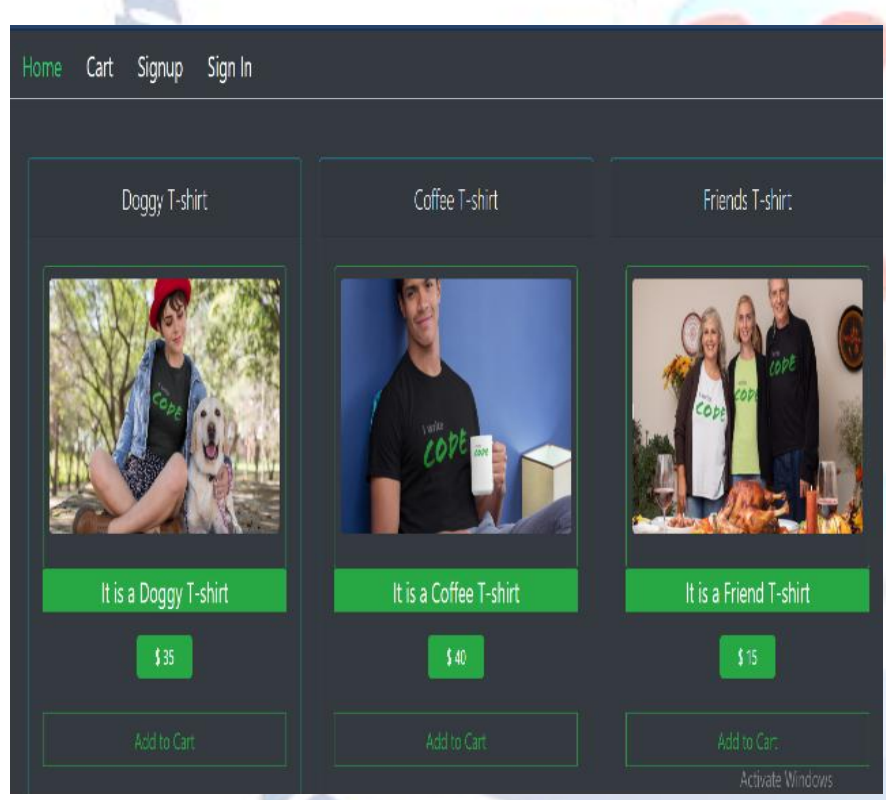

Sign in and Sign up

These two-option redirect to the page where the user can find a form to fill either to create an account or to sign in to an account.

Cart

After selecting any product users can see their product on this page and here the payment will be carried on. Stripe Payment is included for the cart which was a third-party tool that helps users to done payment by some debit cards, credit cards, UPI's.

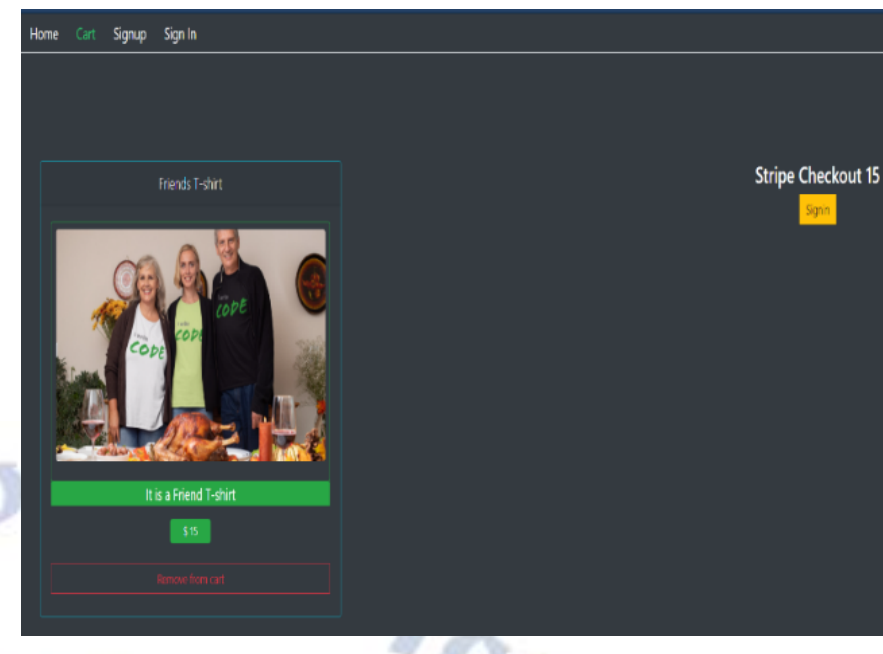

Dashboard:

This page will be different for the user. Admin Dashboard will have a chance to create some categories and can add products to those categories, as well as admin can delete products and he can change prices also.

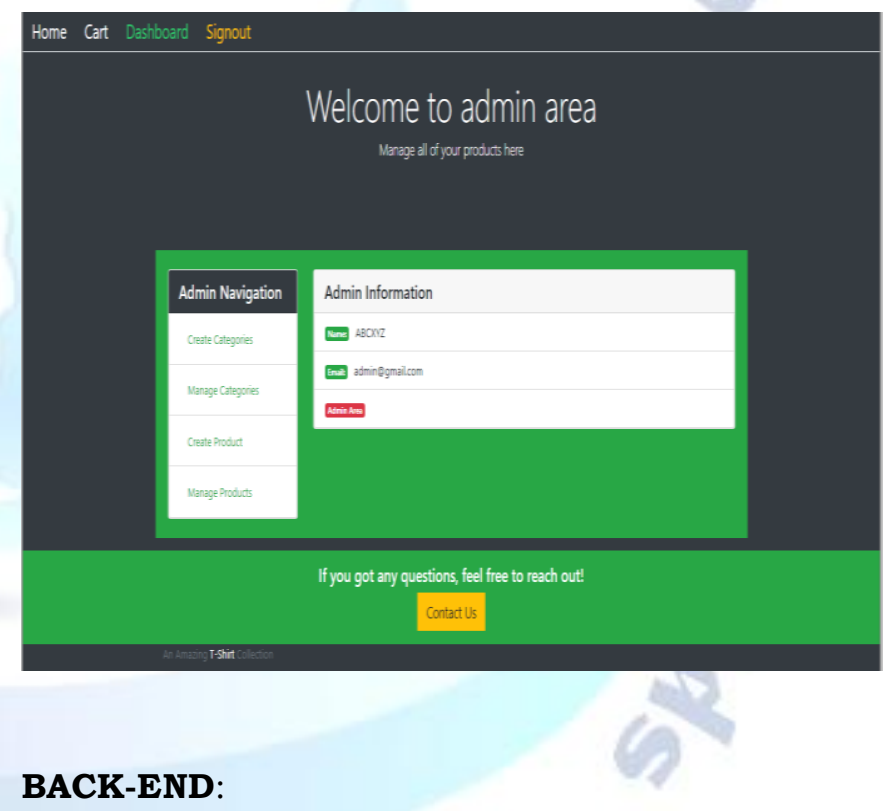

Models:

Here we define the structure of the data that should in the database. By using some models which help to store the data in the database like mongoose, it is one of the famous libraries in NodeJS.

Creating the schemas by mongoose with can mentions the names and type of the data.

\section{Routers:}

All the work related to the routing of the pages was done here. ExpressJS is a popular library form routing. CURD operations and routing-related code are saved in this folder. 


\section{Controllers:}

In controllers, the definitions of the functions which are declared in the routing will be stored and also the codes of the middleware are stored in this folder.

In the controller phase, the function definitions of the function which are declared in the Routers will be done. We are having some middleware also defined here.

\section{DATABASE:}

Data that is entered by the users will be stored in the database. There are so many databases are been used nowadays. In this project, we have MongoDB as a database.

Using the mongoose library, we can connect to MongoDB. There are so many methods in this library to create schema and also to save the data in the database.

\section{CONCLUSION}

The main them is to build an e-commerce t-shirt selling web application with all three i.e., Front end, back end, and database. This web application is a fully pledged working web application right from the login authentication, admin authorization, add items to cart, using payment gateway. It can be used by any textile industry on either a small scale or a larger scale. The web application is easy for them to access and without any effort categories can be created and products can be added by them. It will be very attractive for the customer to see the products by sitting at home or office. It will be very helpful for the small-scale industries without selling to wholesales, large retails mediators they can directly sell to the customer by saving money for both.

\section{REFERENCES}

[1] Chanana, N., \& Goele, S. (2012). Future of e-commerce in India. International Journal of Computing \& Business Research, 8.

[2] Mai, N. (2020). E-commerce Application using MERN stack.

[3] Ullah, S. E., Alauddin, T., \& Zaman, H. U. (2016, January). Developing an E-commerce website. In 2016 International Conference on Microelectronics, Computing and Communications (MicroCom) (pp. 1-4). IEEE.

[4] King, D. N., \& King, D. N. (2004). Introduction to e-commerce. Prentice Hall.

[5] Nemat, R. (2011). Taking a look at different types of e-commerce. World Applied Programming, 1(2), 100-104.

[6] Niranjanamurthy, M., Kavyashree, N., Jagannath, S., \& Chahar, D. (2013). Analysis of e-commerce and m-commerce: advantages, limitations and security issues. International Journal of Advanced Research in Computer and Communication Engineering, 2(6),
[7] Hoque, S. (2020). Full-Stack React Projects: Learn MERN stack development by building modern web apps using MongoDB, Express, React, and Node. js. Packt Publishing Ltd.

[8] Rossi, G., Schwabe, D., \& Lyardet, F. (1999, November). Web application models are more than conceptual models. In International Conference on Conceptual Modeling (pp. 239-252). Springer, Berlin, Heidelberg.
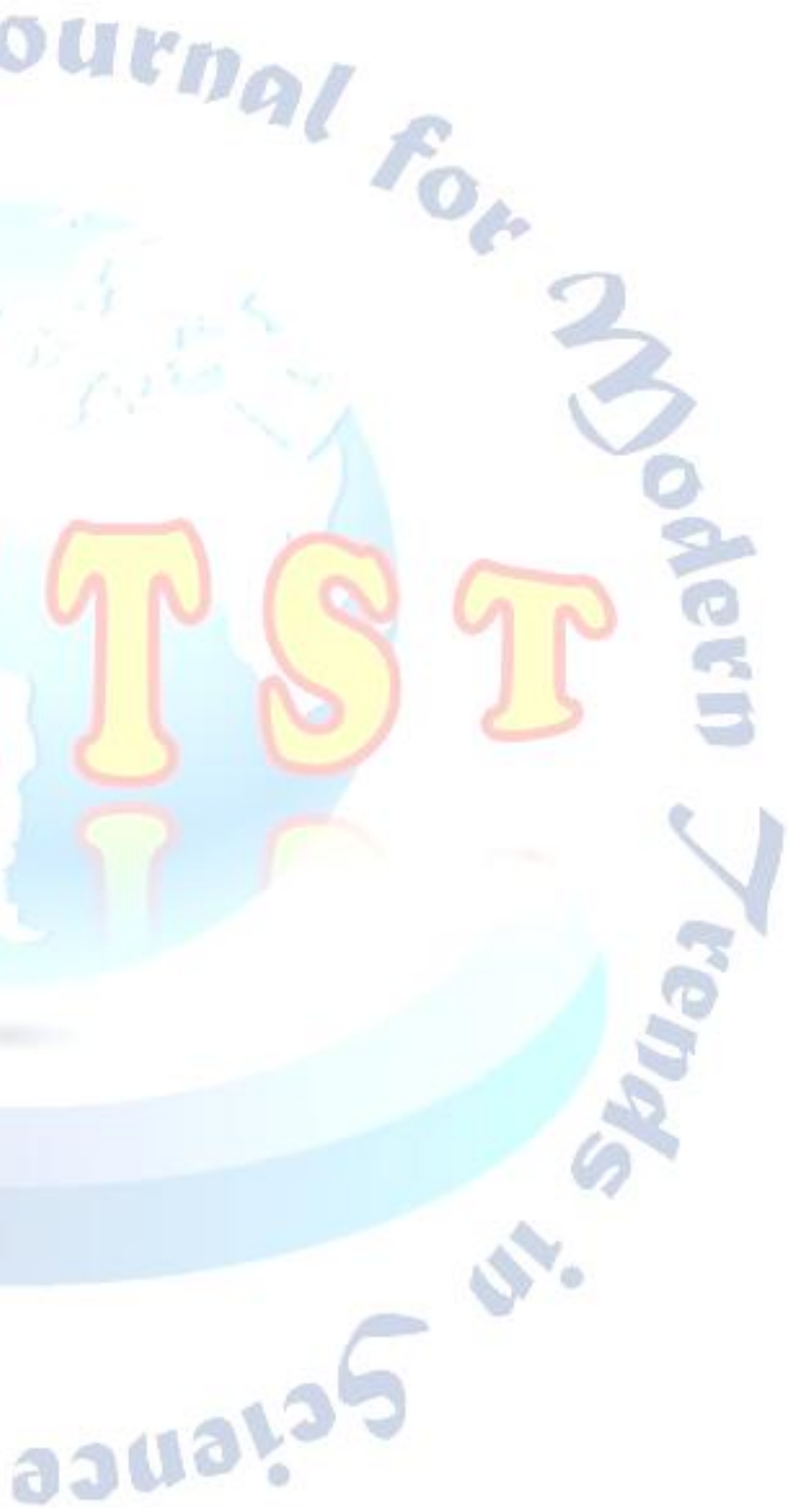